\title{
Assisted Software Design of a Wide Variety of Windings in Rotating Electrical Machinery
}

\author{
A. O. Di Tommaso, F. Genduso, R. Miceli - Member IEEE, C. Spataro \\ DEIM, Department of Energy, Information engineering and Mathematical models, \\ University of Palermo, Viale delle Scienze, block 9, Palermo, Italy. \\ email: antoninooscar.ditommaso@unipa.it
}

\begin{abstract}
In this paper a software developed by the Authors for winding design is presented. In particular, this software can be used as a valid aid in design and analysis for a wide variety of windings with generic number of phases, pole pairs, slot number, etc.. The calculation of winding factors and the evaluation of their harmonic distribution is also accomplished. The software is implemented in MATLAB $®$ environment. By means of some examples, covering the most relevant winding types, the capabilities of this software will be shown. Particularly, integer and fractional slot, single and double layer winding, concentrated windings, imbrication, belt widening and belt shifting techniques can be treated in order to reduce particular harmonics in the electromotive force (e.m.f) or in the magnetic field (m.m.f.=magneto motive force). Thanks to this software it is possible to determine quickly the winding connections. Moreover, the winding factor harmonic distribution, the THD of e.m.f., the differential leakage and the spatial distribution of the m.m.f. is computed in a very easy way.
\end{abstract}

Index Terms-winding, winding factors, differential leakage, winding connections, harmonics, m.m.f., flux density.

\section{LIST OF SYMBOLS}

$N$

$p$

$\mu$

$t$

$m$

$\gamma$

$l_{y}$

$y$

$y_{b}$

$y_{k}$

$k_{w \nu^{\prime}}$

$\nu_{x}^{\prime}$ number of slots;

number of pole pairs;

integer number;

greatest common divider (GCD) between $N$ and $p$, $t=G C D(N, t)$;

number of phases;

nr. of coil sides per phase (nr. of coils per phase for double layer windings);

number of winding layers;

coil pitch (for two layer windings) measured in slots; belt shifting pitch measured in slots;

value of the air-gap m.m.f. distribution at k-th slot;

group factor for the $\nu^{\prime}$-th harmonic order;

maximum harmonic order.

\section{INTRODUCTION}

Long-term operations of electrical motors and generators are expected to have high energetic efficiency as one of the most important goals to reach specifically in renewable energy systems [1]-[7]. Moreover, most electric machine designs rely on the fundamental flux wave theory, focusing its attention on the achievement of a sinusoidal flux density distribution in the air gap with the lowest possible harmonic content [8]-[13]. In some cases this task is regarded as less important and attention is turned on different design criteria [10], [14].
Winding factors, and consequently the harmonic content of the machines electrical quantities, are heavily determined by the type of winding. Particularly, the harmonic distortion of voltages, currents, flux densities, etc., due to the type of winding, affects in a significant manner both the dynamic and steady state performances and their efficiency, by introducing, for example, asynchronous, synchronous and torsional torques, axial, radial forces producing vibrations (and noise), and, last but not least, producing an increase in copper and iron losses. It is, therefore, important to have a clear overview on the winding factor harmonics of electrical machines indeed just in the design phase, i.e. when the right type of winding is to be chosen [15]-[17]. In the perspective of designers many software have been developed to solve magnetic field problems on electrical rotating machines, basing on finite element computing techniques; other softwares have been developed to solve more general problems on power electronic systems, electrical networks or electro-mechanical system [18]-[20]. Unfortunately, not many softwares deal with windings and their design.

In this paper a software developed for winding design is presented. This software is conceived as an aid to simplify and accelerate the design procedures in electrical machine windings. It is also capable to represent numerically the winding connections, for single and double layer structures, and to compute phase leakage factors, field and voltage THDs.

\section{Winding REPRESENTATION AND PROCEDURE FOR WINDING DETERMINATION}

As demonstrated in [21], [22] it is possible to design windings of electrical machines without the aid of a slot star nor of a slot plan (winding scheme), but simply through formulas. These formulas are derived by applying the "generic slot star" as defined in [21], [23] and can be used to form a generic $m \times l_{y} \cdot N / m$ (or, equivalently, $m \times l_{y} \cdot 2 p q$ ) matrix, defined in the following way,

$$
\text { Conn }_{h, \mu}=\left[\begin{array}{ccccc}
a_{1,1} & a_{1,2} & a_{1,3} & \ldots & a_{1, l_{y} \cdot N / m} \\
a_{2,1} & a_{2,2} & a_{2,3} & \ldots & a_{2, l_{y} \cdot N / m} \\
\vdots & \vdots & \vdots & \ddots & \vdots \\
a_{m, 1} & a_{m, 2} & a_{m, 3} & \ldots & a_{m, l_{y} \cdot N / m}
\end{array}\right]
$$

$a_{h, i}$ being positive or negative integer numbers. This matrix represents, mathematically, the connection order of the coil 


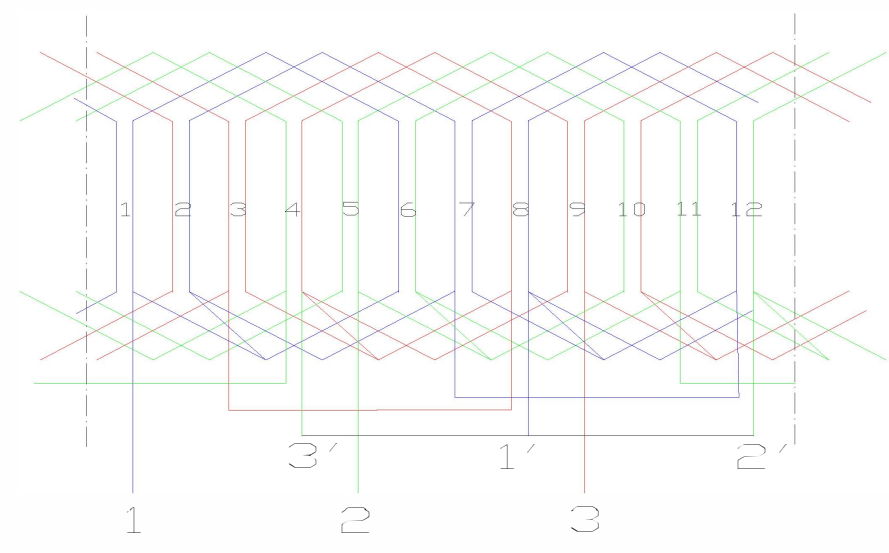

Figure 1. Winding connection scheme of the machine with $N=12, p=1$, $m=3$, double layer with $y=5$.

sides located in each slot. Here $q=\frac{N}{2 p m}$ is the number of slots per pole and per phase. Particularly, the matrix defined by (1), whose $m$ rows, each corresponding respectively to phases 1 , $2,3, \ldots m$, contain a sequence of numbers representing how the coil sides (located within each slot) are to be connected in series to form the $m$ phase sections of the winding. In other words each row element represents the slot number in which a particular coil side is located. The sign of each number defines the e.m.f. or current direction with respect to a chosen reference.

For the sake of clarity an example is presented in the following regarding a 3-phase machine with a double layer winding. In this case (i.e. for a double layer) the number of columns is 8 because $l_{y}=2$, so that $l_{y} N / m=2 \cdot 12 / 3=8$.

Example 1. $N=12, p=1, m=3$, double layer with $y=5$. For this type of winding the connection matrix is

$$
\left[\begin{array}{cccccccc}
1 & -6 & 2 & -7 & -7 & 12 & -8 & 1 \\
5 & -10 & 6 & -11 & -11 & 4 & -12 & 5 \\
9 & -2 & 10 & -3 & -3 & 8 & -4 & 9
\end{array}\right]
$$

and its corresponding scheme is shown in fig. 1.

The general task to determine the $l_{y}$-layer winding connections, i.e. the previously defined connection matrix, of a machine with $N$ slots, $2 p$ poles and $m$ phases can be carried out by the following procedure proposed in [21], [24] and here briefly described:

1) determination of the GCD between $N$ and $p(t)$;

2) calculation of the number of slots containing phase coil sides with the same current (e.m.f.) orientation

$$
\gamma= \begin{cases}\frac{N}{2 \cdot m} & \text { for single layer windings } \\ \frac{N}{m} & \text { for double layer windings }\end{cases}
$$

3) if $\gamma$ is an integer number and if (3) is verified

$$
\begin{cases}\frac{2 \gamma}{t}=i n t & \text { for single layer windings } \\ \frac{\gamma}{t}=i n t & \text { for double layer windings }\end{cases}
$$

then a symmetrical winding can be designed ${ }^{1}$;

4) calculation of the winding slot pitch $y_{N}$;

5) calculation of the phase pitches $y_{1}, y_{2}, \ldots y_{m}$;

6) determination of the negative slot pitch $y_{(-)}$;

7) $\gamma$ positive coil sides slots of the first phase (phase 1) are located in the slots numbered according to the particular sequence defined in [21];

8) The numbering of $\gamma$ slots belonging to the positive coil sides relative to the second phase con be found by adding the term $y_{2}$ to the coil numbers of the first phase (phase $1)$;

9) The numbering of $\gamma$ slots belonging to the positive coil sides relative to the $m$-th phase con be found by adding the term $y_{m}$ to the coil numbers of the first phase (phase $1)$;

10) the numbering of the slots containing the negative coil sides is defined by adding the terms $y_{(-)}$to the ones containing the positive coil sides.

In order to realize the winding coils it is simply necessary to connect two coil sides having opposite e.m.f. (or current) signs, i.e. connecting a positive coil side (positive slot) to a negative one (negative slot).

\section{WINDING FACTORS}

In this section the mathematical method of winding factors calculation, the determination of their harmonic distribution and the formula of the air gap leakage factor are presented.

As known from the theory of electrical machines [8], [9], [21]-[23] each conductor or group of conductors in a slot is characterized by a particular phasor of the induced e.m.f.. All these phasors can be represented in a polar diagram called slot star or e.m.f. star as the one depicted in fig. 2 .

Once the winding connections are defined by its connection matrix it is possible to determine all the winding factors as it will be explained below.

Traditionally, in the literature (see [8], [9], [21], [22], [25]) many formulas have been proposed for the calculation of these factors, which are quite simple to compute in many cases, if $q$ is an integer number, also by means of pocket calculators. On the other hand, when dealing with fractional slot winding (i.e. when $q$ is a fractional number), the spatial distribution of the air-gap magnetic flux density has no half period symmetry; therefore, also the even order harmonics of the air gap magnetic field waves must be considered [8], [9], [22]. This aspect can often yield to complex and tedious calculations.

Furthermore, in case of complex winding configurations, as for example with fractional slot windings where the phase e.m.f. bundles do not show symmetries (see Fig. 2), the winding factors will be made up by more complex formulas [8], [9], [22]. In order to gain generality and to simplify the algorithm, the winding factor is computed as ratio between the geometrical and the algebraic sum of the e.m.f. induced in a winding section (see bundles in fig. 2) [21], [23], [26]:

\footnotetext{
${ }^{1}$ This paper will deal only with symmetrical windings, i.e. with windings for which (2) and (3) are verified at the same time.
} 


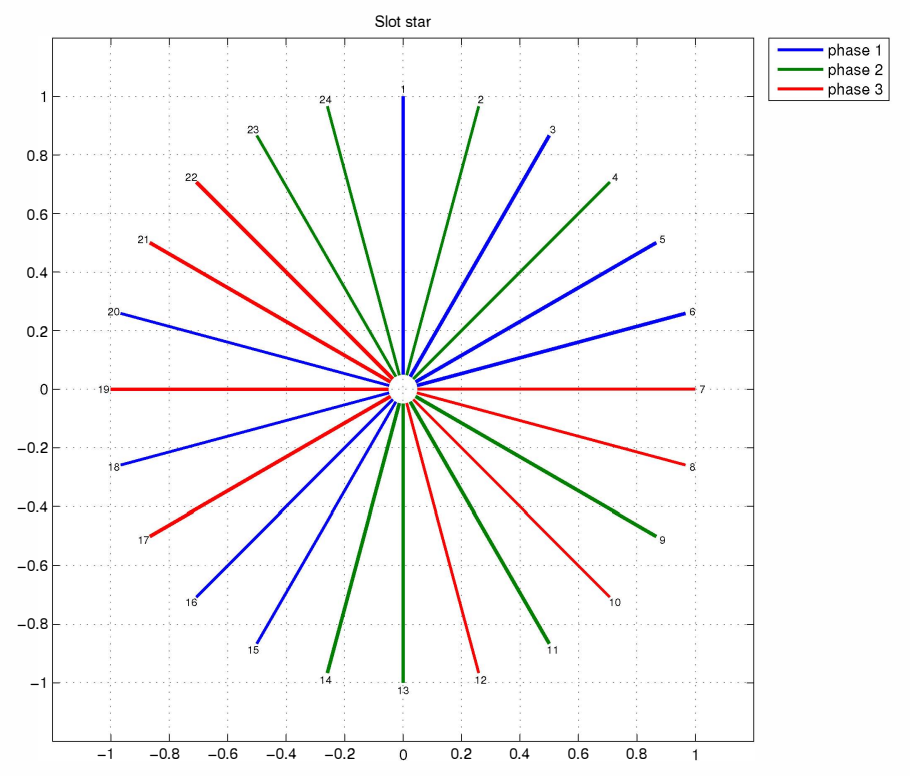

Figure 2. Unsymmetrical phase e.m.f. bundles: winding with $N=24$, $p=1$, with one-sided imbrication of the second order.

$$
k_{w \nu^{\prime}}=\frac{1}{2 p q l_{y}} \cdot \sum_{\mu=1}^{2 p q l_{y}} \sqrt{C_{\nu^{\prime}, \mu}^{2}+S_{\nu^{\prime}, \mu}^{2}}
$$

where

$$
\begin{gathered}
C_{\nu^{\prime}, \mu}=k \cdot \cos \left(\nu^{\prime} \cdot \frac{2 \pi}{N} \cdot\left|\operatorname{Conn}_{h, \mu}\right|\right) \\
S_{\nu^{\prime}, \mu}=k \cdot \sin \left(\nu^{\prime} \cdot \frac{2 \pi}{N} \cdot\left|\operatorname{Conn}_{h, \mu}\right|\right) \\
\nu^{\prime}=p \cdot \nu
\end{gathered}
$$

and

$$
k=\left\{\begin{array}{ll}
+1 & \text { if } \operatorname{Conn}_{h, \mu}>0 \\
-1 & \text { if } \operatorname{Conn}_{h, \mu}<0
\end{array} .\right.
$$

with $\nu^{\prime}=1,2,3, \ldots, \nu_{x}^{\prime}$. Equation (4) is the general formula for winding factor calculation implemented in the MATLAB $®$ program here presented.

In (5), (6) and (8) $h$ represents indifferently one of the $m$ phases because we are dealing with symmetrical windings ${ }^{2}$. It is to be noted that (4) is valid for the determination of the resultant winding factor also in the case of coil pitch shortening; as a matter of fact, information about pitch shortening is already contained in the matrix $\operatorname{Conn}_{h, \mu}$.

Equation (4) is also be used to compute the so called differential leakage factor as [9], [21]-[24], [27]

$$
\sigma_{0}=\left(\frac{\pi}{m k_{w p} l_{y} q}\right)^{2} \cdot 2 \sum_{k=1}^{N} \frac{y_{k}^{2}}{N}-1-\sum_{\nu^{\prime}=1}^{p-1}\left(\frac{k_{w \nu^{\prime}}}{\nu^{\prime} k_{w p}}\right)^{2} .
$$

\footnotetext{
${ }^{2}$ In case of non symmetrical windings $k_{w \nu^{\prime}}$ will generally be different depending on the chosen phase, i.e. depending on index $h$.
}

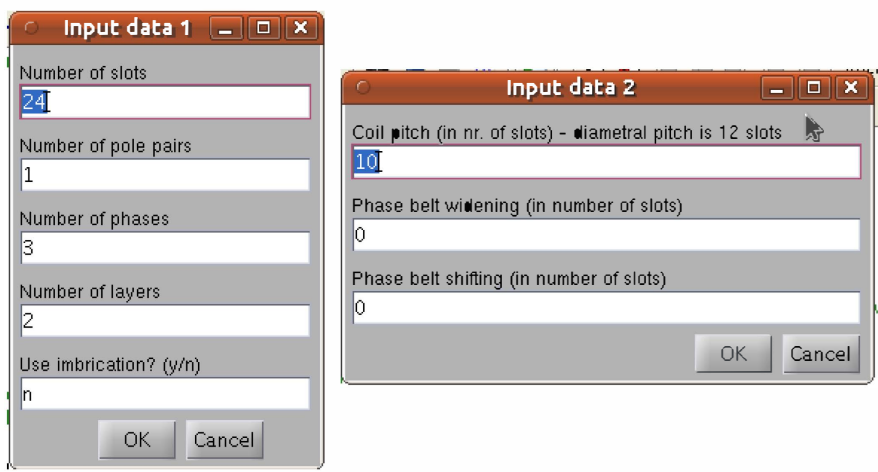

Figure 3. Input windows of the winding software.

The developed MATLAB $®$ software mainly consist of 27 functions. The main data are introduced through two input dialog windows, as shown in fig. 3, accepting the values $N$, $p, m, l_{y}, y, y_{b}$, etc. The output are: the connection matrix $\operatorname{Conn}_{\nu, j}$, which is displayed on the MATLAB ${ }^{\circledR}$ command window, the differential leakage factor $\sigma_{0}$, the THD\% factor of phase and line-to-line machine voltages. Section IV illustrates some examples, referred to 4 particular cases of rotating machine windings, whose results were obtained with the developed software.

\section{EXAMPLES}

In this section some examples, used to test the program, are presented and briefly discussed.

Example 2. Synchronous 3-phase machine winding with $N=$ 108 slots, $p=5$ and $q=3+3 / 5$. This type of winding can be carried out in 3 different ways:

1) with full-pitch coils ${ }^{3}(y=11)$;

2) with shortened pitch coils $(y=9)$;

3 ) with a so called "double chording", realized with $y=10$ slots and $y_{b}=9$ slots [21], [22], [24].

By introducing these data as input for the MATLAB $®$ function a $3 \times 72$ connection matrix is obtained on its command window, which is graphically shown by means of the e.m.f. phasor star (coil e.m.f. star) ${ }^{4}$ of fig. 4. Figures 5 and 6 show respectively the winding factor harmonic distribution and the spatial distribution of the m.m.f..

Table I summarize the main results regarding the THD\% and the differential leakage factors (determined by means of 9) of example 2, while table II summarizes the first 6 relevant winding factor harmonics, demonstrating that a correct choice of winding chording parameters can be very useful in order to improve machine air-gap waveforms.

Example 3. Synchronous machine with a 1-phase double layer winding. The data are: $N=60$ slots, $p=1, q=20$. The winding can be carried out in 3 different ways:

\footnotetext{
$3_{\text {i.e. single layer. }}$

${ }^{4}$ As a matter of fact, when dealing with double layer windings, the phasors of the star represent not the slot e.m.f.s but the coil e.m.f.s.
} 


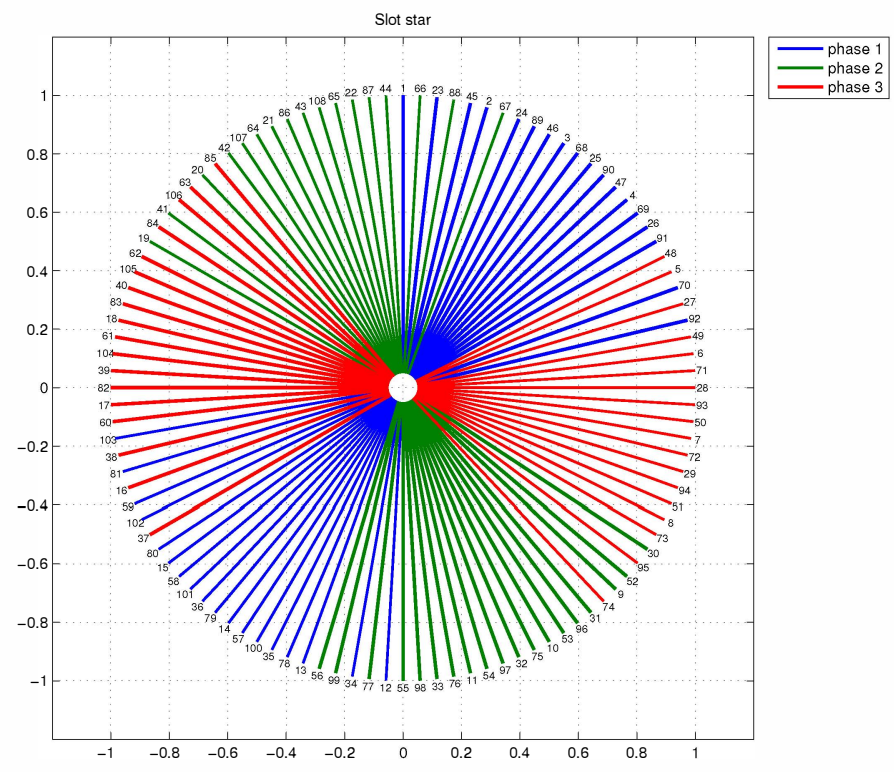

Figure 4. Coil e.m.f. star of the 3-phase machine with $N=108, p=5$, double chording $\left(y=9\right.$ and $\left.y_{b}=7\right)$.

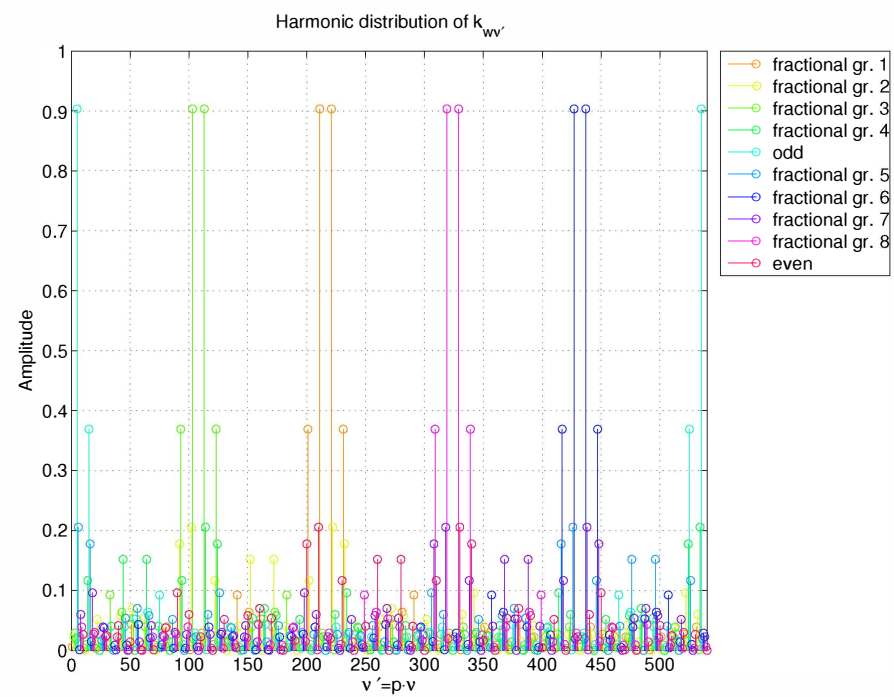

Figure 5. Winding factor harmonics of the 3-phase machine with $N=108$, $p=5$, double chording $\left(y=9\right.$ and $\left.y_{b}=7\right)$.

Table I

VALUES OF THD $\%$ AND $\sigma_{0}$ FOR THE WINDING OF EXAMPLE 2 AND FOR 3 DIFFERENT CONFIGURATIONS.

\begin{tabular}{c|c|c|c} 
Winding & THD\%e & THD\% $v_{l l}$ & $\sigma_{0}$ \\
\hline \hline no chording & 5,3470 & 1,3307 & 4,3199 \\
\hline$y=9$ & 5,0512 & 1,0872 & 1,7969 \\
\hline $\begin{array}{c}y=9 \\
y_{b}=7\end{array}$ & 5,1272 & 1,2920 & 5,4725
\end{tabular}

Table II

VALUES OF THE MOST RELEVANT HARMONICS OF THE WINDING OF EXAMPLE 2 AND FOR THE 3 DIFFERENT CONFIGURATIONS.

\begin{tabular}{c|c|c|c|c|c|c} 
Winding & $\nu=1$ & 3 & 5 & 7 & 9 & 11 \\
\hline \hline no chording & 0,955 & 0,637 & 0,192 & 0,137 & 0,215 & 0,088 \\
\hline$y=9$ & 0,923 & 0,451 & 0,050 & 0,036 & 0,152 & 0,085 \\
\hline $\begin{array}{c}y=9 \\
y_{b}=7\end{array}$ & 0,903 & 0,369 & 0,026 & 0,005 & 0,039 & 0,053
\end{tabular}

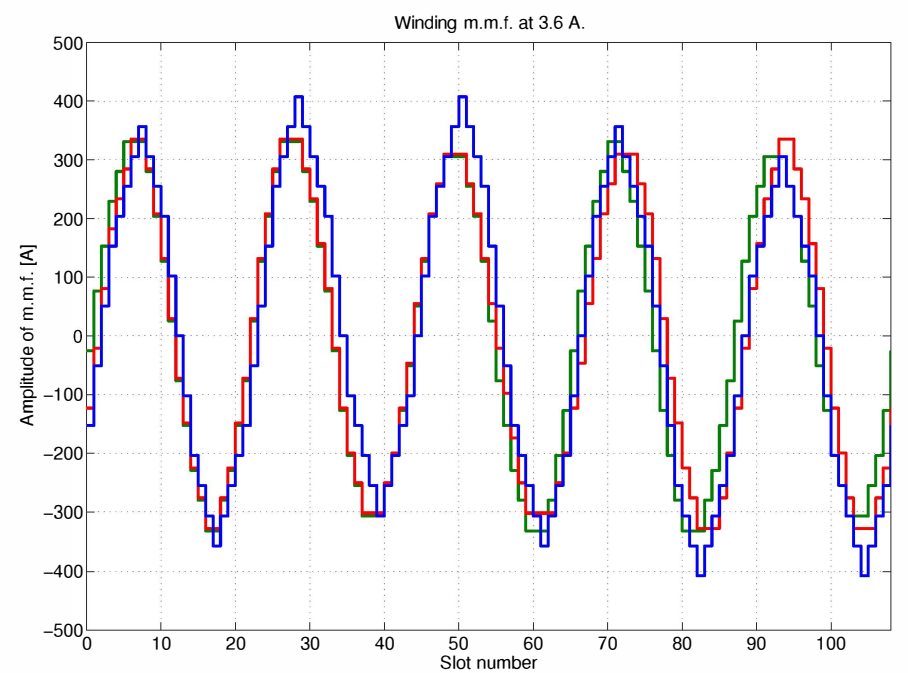

Figure 6. Air gap m.m.f distribution of the 3-phase machine with $N=108$, $p=5$, double chording $\left(y=9\right.$ and $\left.y_{b}=7\right)$.

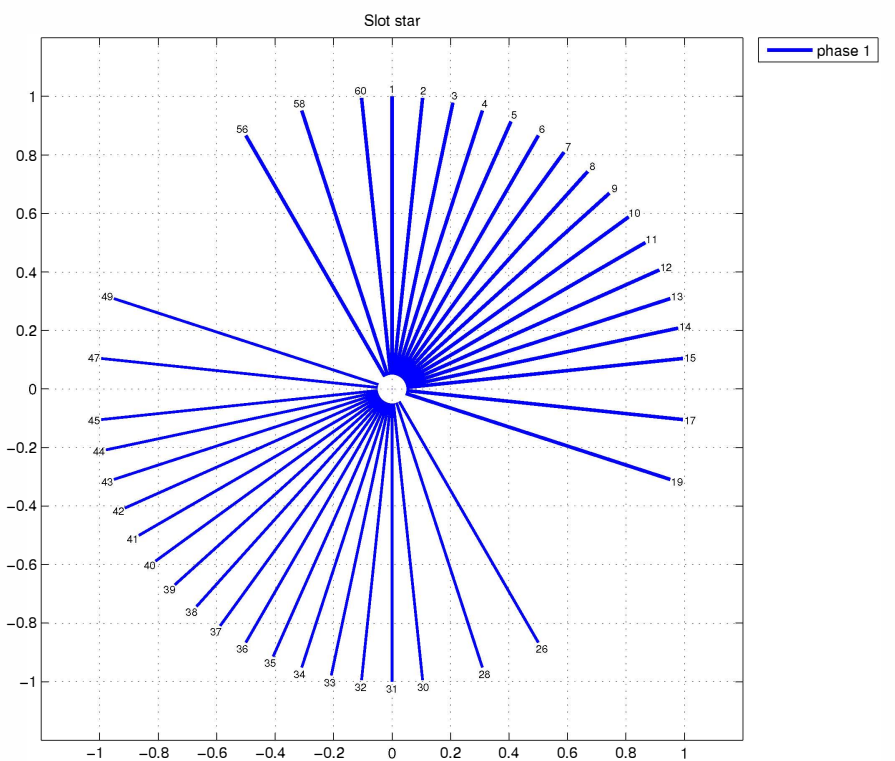

Figure 7. Coil e.m.f. star of the 1-phase machine with $N=60, p=1$, double chording $\left(y=24\right.$ and $\left.y_{b}=25\right)$.

1) with full-pitch coils $(y=30)$;

2) with shortened pitch coils $(y=24)$;

3 ) with a so called "double chording", realized with $y=24$ and $y_{b}=25$ slots [21], [22], [24].

By introducing these data as input for the MATLAB ${ }^{\circledR}$ function a $1 \times 120$ connection matrix is obtained on its command window which is graphically represented by means of the star of fig. $7^{5}$. The three air-gap m.m.f. spatial waves computed for each case are depicted in Fig. 8.

Fig. 9 shows the winding factor harmonic distribution of the 1-phase winding. It is to be noted that in this case only odd harmonics are present, i.e. all even ones are zero, and that all harmonics multiple of 3 are also zero.

$5_{\text {see footnote } 4}$ 


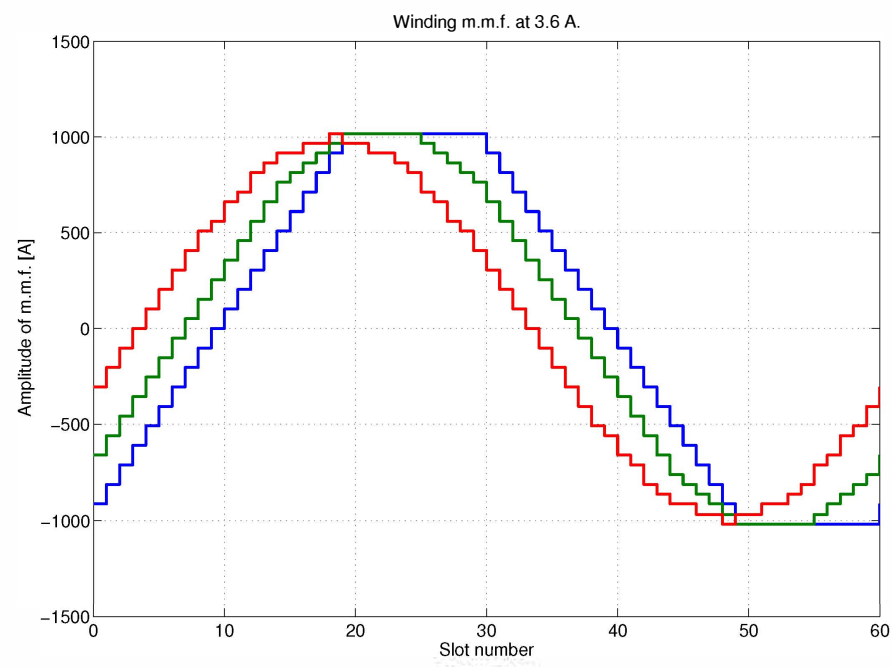

Figure 8. Air gap m.m.f distribution of the 1-phase machine with $N=60$, $p=1$, for: 1) no chording (blue), 2) single chording with $y=24$ (green) and 3) double chording with $y=24$ and $y_{b}=25$ (red).

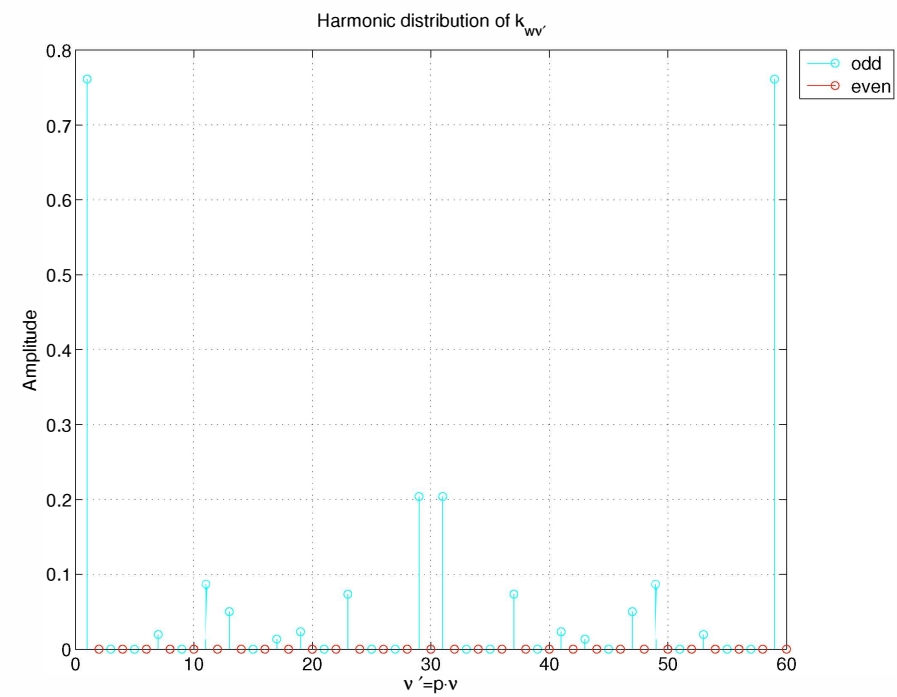

Figure 9. Winding factor harmonics of the 1-phase machine with $N=60$, $p=1$, for the case of double chording $\left(y=24\right.$ and $\left.y_{b}=25\right)$.

The quality of the waveforms can be evaluated by inspection of table III. Table IV summarizes the first 6 relevant winding factor harmonics and demonstrates that a correct choice of winding chording parameters can be very useful in order to improve the m.m.f. wave (see also fig. 8). As a matter of fact by using a double chorded winding it is possible to obtain a m.m.f. spatial distribution shape very close to a sinusoidal one.

Further examples are here presented showing only the star of e.m.f.s.

Example 4. Synchronous machine with a 3-phase double layer fractional concentrated winding. The data are: $N=18$ slots, $p=8, q=3 / 8, y=1$.

Example 5. Machine with a 5-phase double layer fractional
Table III

VALUES OF $T H D \%$ AND $\sigma_{0}$ FOR THE WINDING OF EXAMPLE 3 AND FOR 3 DIFFERENT CONFIGURATIONS.

\begin{tabular}{c|c|c|c} 
Winding & THD $_{B}$ & THD $_{\text {e }} h$ & $\sigma_{0}$ \\
\hline \hline no chording & 14,1255 & 2,6142 & 1506,6374 \\
\hline$y=24$ & 13,5901 & 1,8490 & 1503,4155 \\
\hline $\begin{array}{c}y=24 \\
y_{b}=25\end{array}$ & 13,0121 & 1,0765 & 1503,5522
\end{tabular}

Table IV

VALUES OF THE MOST RELEVANT HARMONICS OF THE WINDING OF EXAMPLE 3 AND FOR THE 3 DIFFERENT CONFIGURATIONS.

\begin{tabular}{c|c|c|c|c|c|c} 
Winding & $\nu=1$ & 3 & 5 & 7 & 9 & 11 \\
\hline \hline no chording & 0,828 & 0 & 0,167 & 0,121 & 0 & 0,080 \\
\hline$y=24$ & 0,787 & 0 & 0 & 0,071 & 0 & 0,076 \\
\hline $\begin{array}{c}y=24 \\
y_{b}=25\end{array}$ & 0,761 & 0 & 0 & 0,020 & 0 & 0,087
\end{tabular}

winding. The data are: $N=70$ slots, $p=2, q=3+1 / 2$, $y=15$ (see fig. 11).

\section{Conclusions}

In this paper a software written in MATLAB® language was synthetically presented and tested by means of 5 examples. The software can be used as a winding design tool as well as a winding analysis tool both for integer and fractional slot windings, because it is capable:

1) to determine schematically the connection order of the coil sides located in machine slots;

2) to determine the spectral distribution of winding factors;

3) to estimate the shape of in a winding induced e.m.f., from air-gap flux density;

4) to estimate the THD and the differential leakage factor.

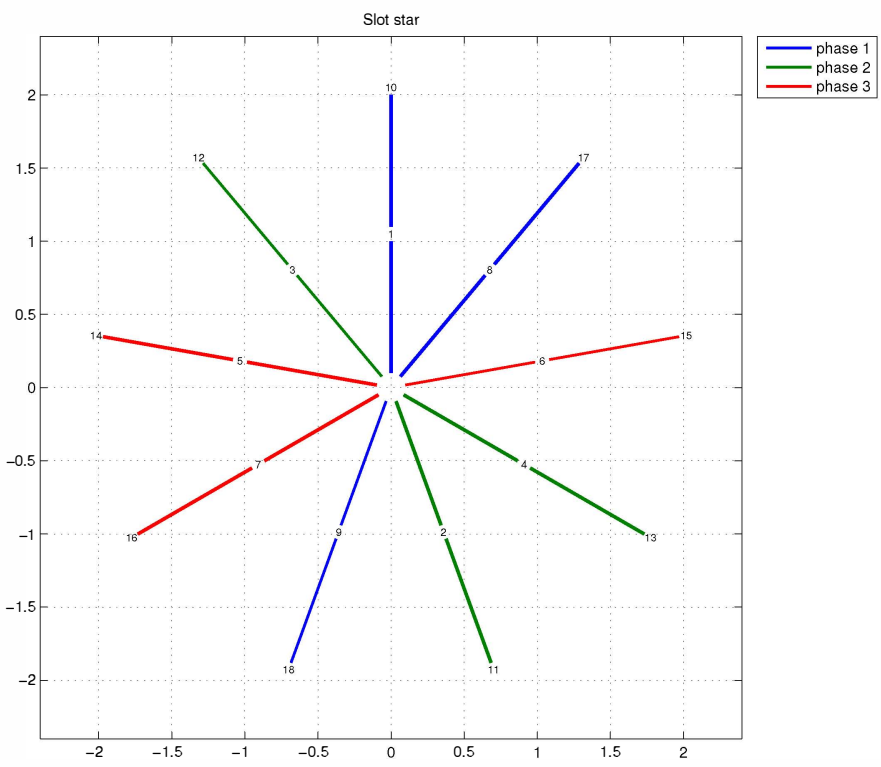

Figure 10. Coil e.m.f. star of the 3-phase machine with $N=18, p=8$, $y=1$ (concentrated winding) 


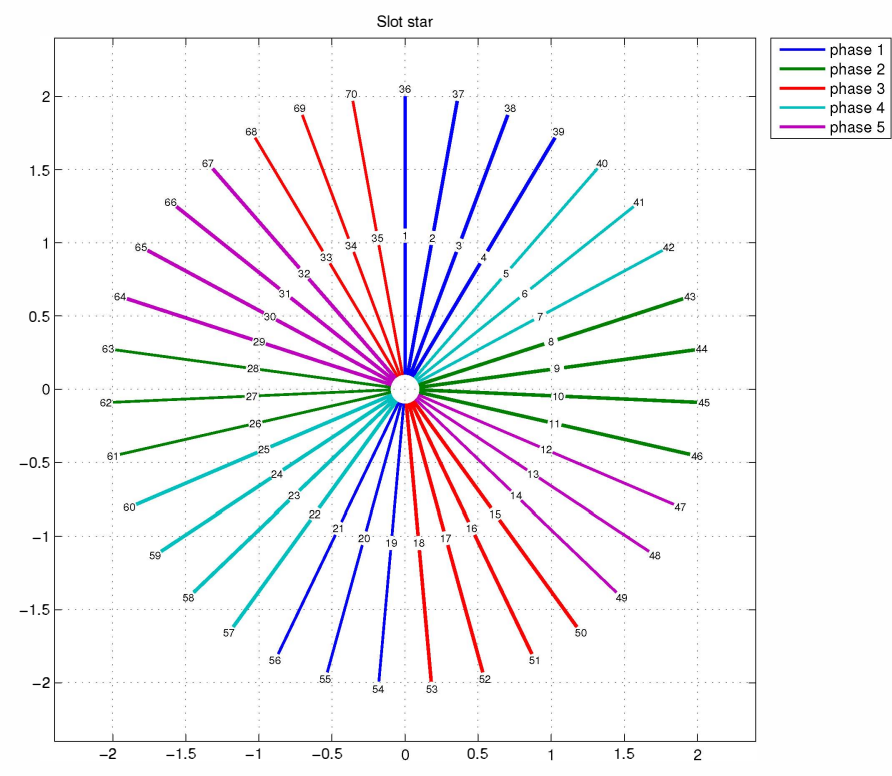

Figure 11. Coil e.m.f. star of the 5-phase machine with $N=70, p=2$, $y=15$.

To run the software and to obtain the above winding data outputs only few elements are required such as: the numbers of slots, pole pairs, phases, etc..

\section{ACKNOWLEDGMENT}

The Authors wish to thank all the collaborators and the staff of SDESLab (Sustainable Development and Energy Savings Laboratory)-University of Palermo. This work was funded by MIUR.

\section{REFERENCES}

[1] C. Cavallaro, A. O. Di Tommaso, R. Miceli, A. Raciti, G. Ricco Galluzzo, and M. Trapanese, "Efficiency enhancement of permanent-magnet synchronous motor drives by online loss minimization approaches," IEEE Transactions on Industrial Electronics, vol. 52, pp. 1153-1160, Aug 2005.

[2] A. O. Di Tommaso, R. Miceli, G. Ricco Galluzzo, and M. Trapanese, "Efficiency Control for Permanent Magnet Synchronous Generators," in IEEE International Conference on Industrial Technology, ICIT 2006. pp. 2079-2084, IEEE, IEEE, December 2006

[3] A. O. Di Tommaso, R. Miceli, G. Ricco Galluzzo, and M. Trapanese, "Efficiency maximization of permanent magnet synchronous generators coupled coupled to wind turbines," in Power Electronics Specialists Conference, 2007. PESC 2007. IEEE, pp. 1267-1272, June 2007.

[4] F. Viola, R. Miceli, P. Romano, and G. Acciari, "On the harvest of rainfall energy by means of piezoelectric transducer," in Proceedings of the International Conference on Renewable Energy Research and Applications (ICRERA), (Madrid, Spain), pp. 1-6, 20-23 October 2013.

[5] V. Boscaino, R. Miceli, G. Capponi, and G. Ricco Galluzzo, "A review of fuel cell based hybrid power supply architectures and algorithms for household appliances," International Journal of Hydrogen Energy, vol. 39, no. 3, pp. 1195 - 1209, 2014.

[6] A. O. Di Tommaso, F. Genduso, and R. Miceli, "Analytical investigation and control system set-up of medium scale pv plants for power flow management," Energies, vol. 5, no. 11, pp. 4399-4416, 2012.

[7] A. O. Di Tommaso, F. Genduso, R. Miceli, and C. Spataro, "Voltage source inverters: An easy approach for fast fault detection," 19th IMEKO TC4 Symposium - Measurements of Electrical Quantities 2013 and 17th International Workshop on ADC and DAC Modelling and Testing, pp. $587-592,2013$

[8] G. Müller and B. Ponick, Theorie elektrischer Maschinen. Elektrische Maschinen, Wiley-VCH Verlag GmbH \& Co KGaA, 6 ed., 2009.
[9] G. Müller, K. Vogt, and B. Ponick, Berechnung elektrischer Maschinen. Elektrische Maschinen, Wiley-VCH Verlag GmbH \& Co KGaA, 6 ed., 2008.

[10] J. Bacher, H. Köfler, and G. Maier, "The use of pitch factor in calculations of AC-machines with concentrated windings," in EPE 2005, pp. 1-6, European Power Electronics and Drives Association, 2005.

[11] M. Caruso, V. Cecconi, A. O. Di Tommaso, and R. Rocha, "A rotor flux and speed observer for sensorless single-phase induction motor applications," International Journal of Rotating Machinery, vol. 2012, pp. $1-13,2012$.

[12] G. Cipriani, R. Miceli, C. Spataro, and G. Tiné, "Electric power quality evaluation in the presence of electromagnetic emissions," in Proceedings of the International Conference on Renewable Energy Research and Applications (ICRERA), (Madrid, Spain), pp. 1-6, 20-23 October 2013.

[13] G. Cipriani, R. Miceli, and C. Spataro, "Uncertainty evaluation in the measurements for the electric power quality analysis," in Proceedings of the International Conference on Renewable Energy Research and Applications (ICRERA), (Madrid, Spain), pp. 1-6, 20-23 October 2013.

[14] V. Di Dio, G. Cipriani, R. Miceli, and R. Rizzo, "Design criteria of tubular linear induction motors and generators: a prototype realization and its characterization," Leonardo Electronic Journal of Practices and Technologies, vol. 12, no. 23, pp. 19-40, 2013.

[15] A. O. Di Tommaso, G. Ricco Galluzzo, and R. Miceli, "Improvement of IPMSM Performance through a Mixed Radial-tangential Rotor Structure," in IEEE International Symposium on Industrial Electronics (ISIE), (Bari, Italy), pp. 1327-1332, IEEE, 2010.

[16] Y. Gritli, A. O. Di Tommaso, F. Filippetti, R. Miceli, C. Rossi, and A. Chatti, "Investigation of motor current signature and vibration analysis for diagnosing rotor broken bars in double cage induction motors," in International Symposium on Power Electronics, Electrical Drives, Automation and Motion (SPEEDAM), (Sorrento, Italy), pp. 1360-1365, 20-22 June 2012.

[17] A. O. Di Tommaso, F. Filippetti, Y. Gritli, R. Miceli, and C. Spataro, "Double squirrel cage induction motors: A new approach to detect rotor bar failures," 19th IMEKO TC4 Symposium - Measurements of Electrical Quantities 2013 and 17th International Workshop on ADC and DAC Modelling and Testing, pp. 671-676, 2013.

[18] A. O. Di Tommaso, F. Genduso, R. Miceli, and G. Ricco Galluzzo, "Computer aided optimization via simulation tools of energy generation systems with universal small wind turbines," in 3rd IEEE International Symposium on Power Electronics for Distributed Generation Systems (PEDG), 2012, pp. 570-577, June 2012.

[19] A. Tessarolo, M. Mezzarobba, and M. Degano, "Analytical calculation of air-gap armature reaction field including slotting effects in fractionalslot concentrated-coil SPM multiphase machines," in 2011 International Conference on Power Engineering, Energy and Electrical Drives (POWERENG), pp. 1-6, May 2011.

[20] V. Cecconi, V. Di Dio, A. O. Di Tommaso, S. Di Tommaso, D. La Cascia, and R. Miceli, "Active power maximizing for wind electrical energy generating systems moved by a modular multiple blade fixed pitch wind turbine," in Power Electronics, Electrical Drives, Automation and Motion, 2008. SPEEDAM 2008. International Symposium on, pp. 1460-1465, June 2008.

[21] H. Sequenz, Die Wicklungen elektrischer Maschinen: Wechselstrom Ankerwicklungen., vol. 1. Springer Verlag, 1950.

[22] R. Richter, Lehrbuch der Wicklungen elektrischer Maschinen. Wissenschaftliche Bücherei, Verlag und Druck G. Braun, 1952.

[23] A. O. Di Tommaso, F. Genduso, and R. Miceli, "A software for the evaluation of winding factor harmonic distribution in high efficiency electrical motors and generators," in 2013 8th International Conference and Exhibition on Ecological Vehicles and Renewable Energies (EVER), pp. 1-6, March 2013

[24] H. Sequenz, Die Wicklungen elektrischer Maschinen: WechselstromSonderwicklungen, vol. 3. Springer Verlag, 1954.

[25] R. Richter, Allgemeine Berechunungselemente - Gleichstrommaschinen, vol. 1 of Elektrische Maschinen. Basel, Stuttgart: Birkhäuser, 3 ed., 1967.

[26] H. W. Böller and H. Jordan, "Über die phasenrichtige Addition der nutharmonischen Wicklungsoberfelder und der Nutungsoberfelder bei phasenreinen Mehrphasenwicklungen," ETZ-A, vol. 84, no. 7, pp. 235238, 1963.

[27] R. Richter, Die Induktionsmaschinen, vol. 4 of Elektrische Maschinen. Basel, Stuttgart: Birkhäuser, 2 ed., 1954. 